$\beta$-agonists and 27 (14\%) subjects were taking $\beta$-blockers. Only one $(0.5 \%)$ patient was taking both.

$\beta_{1}$-receptors are much more prevalent in the heart, while $\beta_{2^{-}}$ receptors are prevalent in bronchial smooth muscle [3]. The original evidence of adverse effects of $\beta$-blockers on airways was based on early case reports of acute bronchospasm associated with high doses of nonselective $\beta$-blockers [1]. Since then, cardioselective $\beta$-blockers have been developed that have $>20$ times the affinity for $\beta_{1}$ - than $\beta_{2}$-receptors and are therefore less likely to cause bronchospasm. It is valid to use cardioselective $\beta$-blockers in low-risk respiratory patients with high-risk cardiac conditions, but this should be done with close monitoring [4]. As cardioselective $\beta$-blockers are increasingly prescribed, it is not surprising that $67 \%$ of patients in our survey were using them. However, $33 \%$ of patients were taking nonselective $\beta$-blockers, which have not been shown to be safe in airways disease. Eight $(30 \%)$ of the patients in our survey were on a $\beta$-blocker solely for hypertension, even though $\beta$-blockers are no longer regarded as first-line treatment for hypertension [5].

Concomitant use of $\beta$-agonist and $\beta$-blocker drugs does not appear to be common. The in-patient point prevalence was $0.5 \%$ and over a 2-yr period, in a variety of settings, we encountered only 34 examples (27 analysed). Our survey suggests that coprescription of these drugs may often be inadvertent and that in some patients with airways disease, $\beta$-blockers could be stopped or a cardioselective $\beta_{1}$-antagonist substituted.
Y. Ling, W. Saleem and C.D. Shee

Dept of Medicine, Queen Mary's Hospital, Sidcup, UK.

\section{STATEMENT OF INTEREST}

None declared.

\section{REFERENCES}

1 Salpeter SR, Ormiston TM, Salpeter EE. Cardioselective $\beta$ blockers in patients with reactive airway disease: a metaanalysis. Ann Intern Med 2002; 137: 715-725.

2 Salpeter SR, Ormiston TM, Salpeter EE, Poole PJ, Cates CJ. Cardioselective $\beta$-blockers for chronic obstructive pulmonary disease: a meta-analysis. Respir Med 2003; 97: 1094-2101.

3 Salpeter SR, Buckley NS. Use of $\beta$-blockers and $\beta$-agonists in COPD: a review of clinical outcomes. Respir Med: COPD update 2007; 2: 133-139.

4 Ashrafian H, Violaris AG. $\beta$-blocker therapy of cardiovascular diseases in patients with bronchial asthma or COPD: The pro viewpoint. Prim Care Respir J 2005; 14: 236-241.

5 The National Collaborating Centre for Chronic Conditions. Hypertension: Management in Adults in Primary Care: Pharmacological Update. London, Royal College of Physicians, 2006.

DOI: $10.1183 / 09031936.00153707$

\title{
Meta-analysis may not be practicable for guiding antibiotic therapy
}

\section{To the Editors:}

We read with interest a meta-analysis by SIEMPOS et al. [1] that showed that macrolides, quinolones and amoxicillin/clavulanate might be considered equivalent for treating acute bacterial exacerbation of chronic bronchitis. Despite meticulous adherence to the methodology of meta-analysis and a comprehensive discussion of the major limitations of their study, the investigators might have used an inappropriate tool for addressing a common clinical problem.

Although meta-analysis has been placed at the pinnacle of the hierarchy of clinical evidence [2], caution is required for clinical scenarios in which targeted pathogens and their drug sensitivity patterns may vary with geographical location and time. One such scenario is the antibiotic treatment of lower respiratory tract infection, including pneumonia and chronic bronchitis, for which the clinical decision is often empirical and heavily dependent upon timely and relevant epidemiological data, as well as the patient's clinical characteristics $[3,4]$. Fundamental differences in these major factors that existed between the study populations from different locations and periods would have rendered it meaningless to find summary estimates with meta-analysis.

The only valid finding may be their conclusion about the significantly higher association between adverse effects and amoxicillin/clavulanate in comparison with quinolones, since adverse events may be subject to less variation due to time, place and person. That notwithstanding, the choice of antibiotic for empirical treatment must also take into account the inherent diagnostic uncertainty and long-term implications for resistance profiles. In this regard, fluoroquinones have been incriminated in causing a delay in the diagnosis of tuberculosis [5]. Thus, fluoroquinolones have been reserved for use only in certain settings in some tuberculosis-endemic populations.

\section{K.C. Chang and C.C. Leung}

Tuberculosis and Chest Service, Centre for Health Protection, Department of Health, Hong Kong, China.

\section{STATEMENT OF INTEREST}

None declared. 


\section{REFERENCES}

1 Siempos II, Dimopoulos G, Korbila IP, Manta K, Falagas ME. Macrolides, quinolones and amoxicillin/clavulanate for chronic bronchitis: a meta-analysis. Eur Respir J 2007; 29: 1127-1137.

2 Guyatt GH, Sackett DL, Sinclair JC, Hayward R, Cook DJ, Cook RJ. Users' guides to the medical literature. IX. A method for grading health care recommendations. Evidence-Based Medicine Working Group. JAMA 1995; 274: 1800-1804.

3 Adams SG, Anzueto A. Antibiotic therapy in acute exacerbations of chronic bronchitis. Semin Respir Infect 2000; 15: 234-247.

4 Mandell LA, Wunderink RG, Anzueto A, et al. Infectious Diseases Society of America/American Thoracic Society consensus guidelines on the management of communityacquired pneumonia in adults. Clin Infect Dis 2007; 44: Suppl. 2, S27-S72.

5 Dooley KE, Golub J, Goes FS, Merz WG, Sterling TR. Empiric treatment of community-acquired pneumonia with fluoroquinolones, and delays in the treatment of tuberculosis. Clin Infect Dis 2002; 34: 1607-1612.

DOI: 10.1183/09031936.00156707

\section{From the authors:}

We thank K.C. Chang and C.C. Leung for their interest in our meta-analysis [1] and we welcome their comments.

As our respectful colleagues acknowledged, a well-designed and carefully performed meta-analysis is graded the highest level of scientific quality by evidence-based movement [2]. It has been stated that a systematic review "faithfully summarizes the evidence from all relevant studies on a topic, and it does so concisely and transparently" [3]. Thus, meta-analyses are consistently used as the basis for a grade A recommendation in clinical practice guidelines, including those dealing with antimicrobial therapy [4]. Convinced by the principles of evidence-based medicine, we attempted to perform several meticulous meta-analyses in the field of antimicrobial treatment for acute bacterial exacerbations of chronic bronchitis (ABECB) $[1,5]$, as well as for other lower respiratory tract infections $[6,7]$.

We are aware that simple pooling of data is not sufficient to ensure the internal validity and, therefore, the generalisability of the findings of a meta-analysis [8]. Thus, we have critically appraised the evidence derived from systematic reviews [9]. For example, in our meta-analysis of the various antimicrobials for $A B E C B$, we insisted on assessing its potential limitations [1]; a great proportion of the Discussion section is devoted to this. We emphasised that "antimicrobial resistance is a moving target and only data from local surveillance studies on this major clinical and public health problem provide information that helps the clinician in decision making regarding the choice of the appropriate antibiotic for a given patient with ABECB" [1]. In addition, in table 1 of the manuscript we carefully listed the characteristics of the subjects included in the individual randomised controlled trials, in order to help the reader determine whether its findings are applicable to his/her patient population [1]. Taking these issues into consideration, we believe that clinicians will find our meta-analysis results valuable while treating patients with $\mathrm{ABECB}$.

Finally, we agree with K.C. Chang and C.C. Leung that several concerns have arisen regarding the usage of fluoroquinolones for the treatment of patients with lower respiratory tract infections in areas with endemicity of tuberculosis [10]. Actually, it could be argued that this fact further underscores the usefulness of the present meta-analysis. Indeed, if clinicians acknowledge that fluoroquinolones are equivalent to macrolides or amoxicillin/ clavulanate for the treatment of patients with acute bacterial exacerbations of chronic bronchitis in terms of their short period of effectiveness, they may prefer to use macrolides or amoxicillin/clavulanate rather than fluoroquinolones in areas with endemicity of tuberculosis.

\section{I.I. Siempos*, G. Dimopoulos*,\# and M.E. Falagas ${ }^{*,+,+}$}

*Alfa Institute of Biomedical Sciences, and "Intensive Care Unit, Attikon University Hospital, and "Dept of Medicine, Henry Dunant Hospital, Athens, Greece. ${ }^{+}$Dept of Medicine, Tufts University School of Medicine, Boston, MA, USA.

\section{STATEMENT OF INTEREST}

None declared.

\section{REFERENCES}

1 Siempos II, Dimopoulos G, Korbila IP, Manta K, Falagas ME. Macrolides, quinolones and amoxicillin/clavulanate for chronic bronchitis: a meta-analysis. Eur Respir J 2007; 29: 1127-1137.

2 Cook DJ, Guyatt GH, Laupacis A, Sackett DL, Goldberg RJ. Clinical recommendations using levels of evidence for antithrombotic agents. Chest 1995; 108: Suppl. 4, 227S-230S.

3 Cook DJ, Murlow CD, Haynes RB. Systematic reviews: synthesis of best evidence for clinical decisions. Ann Intern Med 1997; 126: 376-380.

4 Woodhead M, Blasi F, Ewig S, et al. Guidelines for the management of adult lower respiratory tract infections. Eur Respir J 2005; 26: 1138-1180.

5 Dimopoulos G, Siempos II, Korbila IP, Manta K, Falagas ME. Comparison of first-line with second-line antibiotics for acute exacerbations of chronic bronchitis: a meta-analysis of randomized controlled trials. Chest 2007; 132: 447-455.

6 Siempos II, Vardakas KZ, Manta KG, Falagas ME. Carbapenems for the treatment of immunocompetent adult patients with nosocomial pneumonia. Eur Respir J 2007; 29: 548-560.

7 Falagas ME, Siempos II, Vardakas KZ. Linezolid versus glycopeptide or $\beta$-lactam for treatment of gram-positive bacterial infections: meta-analysis of randomised controlled trials. Lancet Infect Dis 2008; 8: 53-66.

8 Tobin MJ, Jubran A. Meta-analysis under the spotlight: focused on a meta-analysis of ventilator weaning. Crit Care Med 2008; 36: 1-7. 